State \& Alternative Fuel Provider Fleets

\section{Fleet Compliance Annual Report: Model Year 2018, Fiscal Year 2019}

The U.S. Department of Energy (DOE) regulates covered state government and alternative fuel provider fleets, pursuant to the Energy Policy Act of 1992 (EPAct), as amended.

For model year (MY) 2018, the compliance rate with this program for the more than $311^{1}$ reporting fleets was 100\%. Fleets used either Standard Compliance or Alternative Compliance reporting methods.

\section{Fleet Compliance at a Glance}

More than 303 fleets used Standard Compliance and exceeded their aggregate MY 2018 acquisition requirements by $28 \%$ through acquisitions of creditable vehicles, biodiesel, infrastructure, and non-road equipment. The eight covered fleets that used Alternative Compliance exceeded their aggregate MY 2018 petroleum use reduction requirements by $18 \%$.

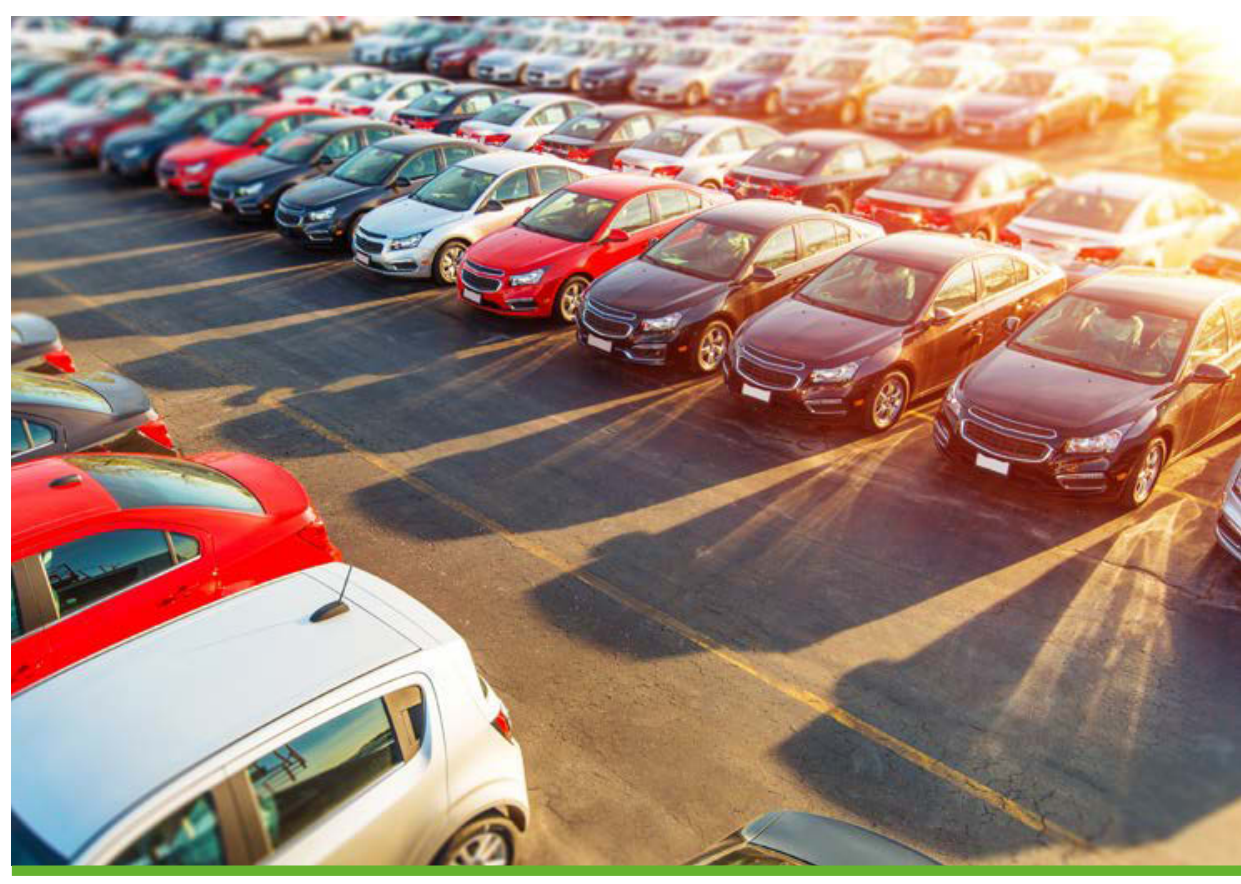

Photo from iStock \#480652712

Overall, DOE saw a decrease from MY 2017 in total biodiesel fuel use as well as a slight decrease in fuel use credits earned; 1,646 biodiesel fuel use credits were earned in MY 2018. There was a decrease in the number of reported light-duty (LD) alternative fuel vehicles (AFVs) acquired, ${ }^{2}$ but an increase in the number of LD vehicles that earned partial credit.

MY 2018 marked the fifth year that fleets complying via Standard Compliance could earn credits for the acquisition of certain non-AFV electric drive vehicles, as well as investments in alternative fuel non-road equipment, alternative fuel infrastructure, and emerging technologies. The data for MY 2018 suggest a continued presence of EPAct-covered state and alternative fuel provider fleets in the AFV, alternative fuel, and advanced technology vehicle markets.

\section{Standard Compliance Results}

Covered state and alternative fuel provider fleets operating under Standard Compliance (10 CFR Part 490, Subpart C or D) achieved compliance by acquiring AFVs and certain non-AFVs; purchasing biodiesel for use in medium- or heavy-duty (MD/ HD) vehicles; investing in alternative fuel infrastructure, non-road equipment, and emerging technology; and/or applying banked credits earned previously or acquired from other covered fleets.

In MY 2018, the fleets that used Standard Compliance:

- Acquired 15,142 LD AFVs

- Earned 756 credits for the acquisition of 1,616 creditable non-AFVs (i.e., hybrid electrics, certain plug-in hybrid electric vehicles [PHEVs], MD/HD

\title{
What Is EPAct?
}

The Energy Policy Act of 1992 (EPAct) was passed by Congress to reduce the nation's dependence on imported petroleum. Provisions of EPAct require certain fleets to purchase AFVs. DOE administers these requirements through its State and Alternative Fuel Provider Fleet Program, Federal Fleet Requirements, and Alternative Fuel Designation Authority.
${ }^{1}$ Some reporting entities represent one agency or business; others represent the fleet operations of multiple entities (e.g., a state or company that reports on behalf of all of its covered state agencies or subsidiaries).

${ }^{2}$ AFVs include any dedicated or dual-fueled vehicle (i.e., any vehicle that operates solely on, or is capable of operating on, at least one alternative fuel). The following fuels are defined or designated as alternative fuels: methanol, denatured ethanol, and other alcohols; blends of $85 \%$ or more of alcohol with gasoline; natural gas and liquid fuels domestically produced from natural gas; liquefied petroleum gas (propane); coal-derived liquid fuels; hydrogen; electricity; fuels (other than alcohol) derived from biological materials (including pure biodiesel [B100]); and three P-series fuels. 


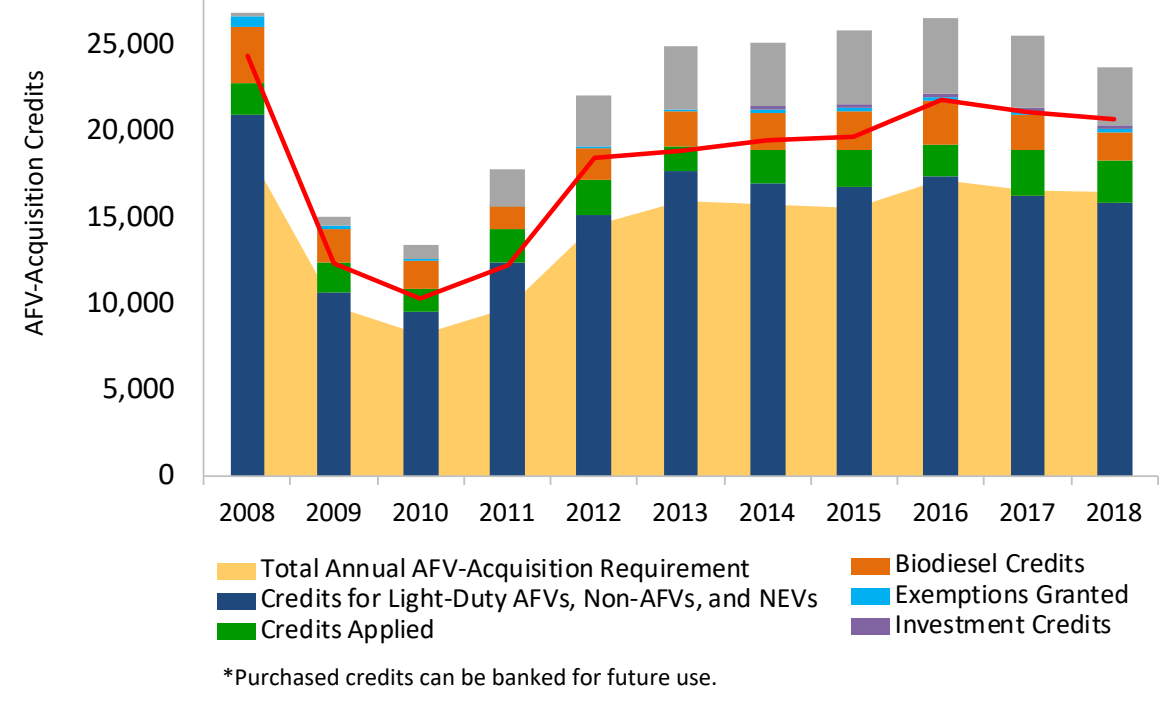

Figure 1. Standard Compliance methods.

electric vehicles, and neighborhood electric vehicles [NEVs])

- Earned 1,646 biodiesel fuel use credits through the purchase of more than 7.9 million gallons of $\mathrm{B} 100^{3}$

- Earned 231 credits for investments of $\$ 18.7$ million in alternative fuel infrastructure and non-road equipment

- Applied 2,435 banked credits.

In addition, these state and alternative fuel provider fleets earned a total of 7,498 bankable AFV credits.

As a whole, the fleets operating under Standard Compliance went beyond compliance, exceeding their AFV-acquisition requirements $(16,486)$ by approximately $28 \%$.

\footnotetext{
3 The credits awarded for biodiesel purchase and use do not necessarily reflect the total amount of biodiesel purchased because each fleet may apply its biodiesel fuel use credits to meet no more than $50 \%$ of its annual $\mathrm{AFV}$-acquisition requirements, and so many fleets do not report the full amount of the biodiesel they use.

${ }^{4}$ To be considered an AFV, the vehicle must be a dedicated vehicle or a dual-fueled vehicle. Some plug-in hybrid electric vehicles are considered AFVs and others are not, depending on whether the vehicle in question meets the "dual-fueled vehicle" definition. For additional information, please review program guidance (epact. energy.gov/pdfs/plug-in_hybrid_electric_vehicles.pdf).
} $(15,714)$. Changes to the program effective in MY 2014 allow covered fleets to earn partial AFV-acquisition credits for the acquisition of some vehicles that are not AFVs.

Specifically, acquiring hybrid electric vehicles (HEVs), PHEVs that are not $\mathrm{AFVs},{ }^{4}$ and $\mathrm{MD} / \mathrm{HD}$ electric vehicles can earn a covered fleet 0.5 credit per vehicle, while the acquisition of NEVs can earn a covered fleet 0.25 credit per NEV.

Acquisition of LD vehicles and NEVs that earned less than a full credit each $(1,606$ vehicles in 2018) resulted in fleets earning a total of 15,895 credits for acquisition of LD vehicles and NEVs in MY 2018 slightly less than in 2017.

The decreases in the number of AFVs and creditable non-AFVs acquired is not unexpected given the decrease in the number of $L D$ vehicles acquired. The total number of vehicles acquired each year by covered fleets has not changed dramatically in recent years. However, the number of categories of vehicles for which credits may now be earned has expanded, resulting in fleets having additional flexibility in meeting their needs. In addition, once covered fleets have achieved compliance, they may earn bankable credits for any MD/ HD vehicles they acquire. In MY 2018, covered fleets earned 3,329 credits for the acquisition of MD/HD vehicles. In total, fleets acquired 20,095 creditable vehicles

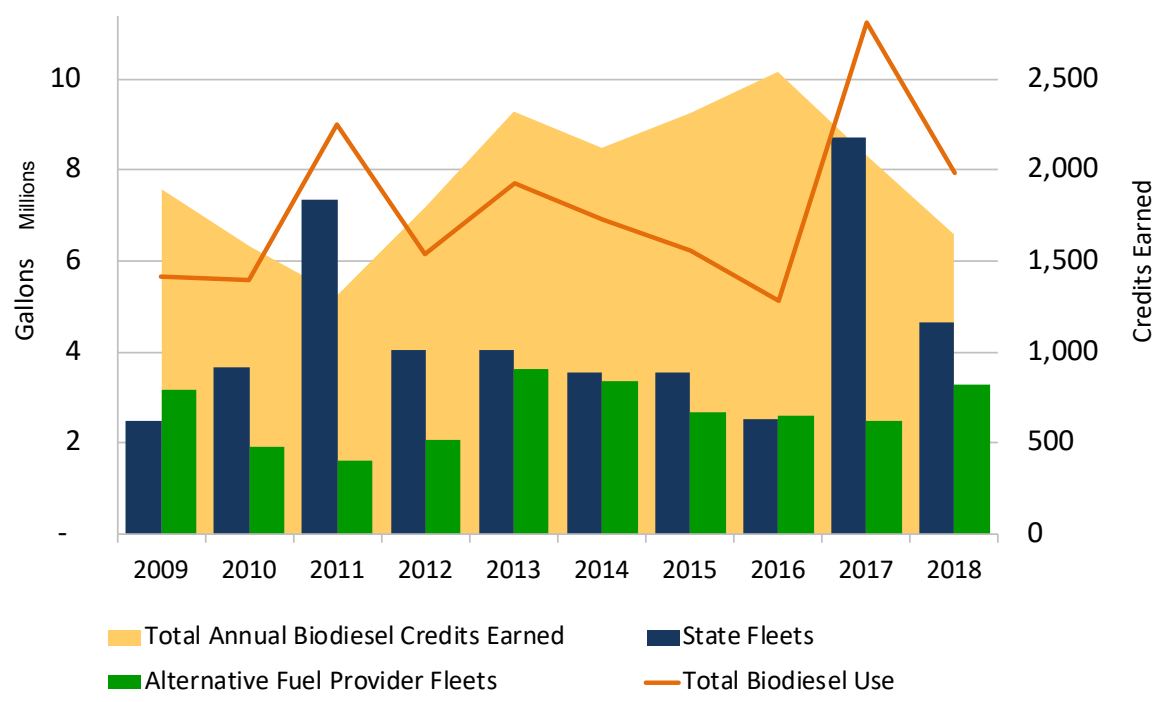

Figure 2. Annual biodiesel (B100) use and biodiesel credits earned. 
of all size categories. Flexible-fuel vehicles accounted for over $85 \%$ of these acquired AFVs.

\section{Biodiesel Fuel Use}

Covered state and alternative fuel provider fleets may earn one biodiesel fuel use credit for every 450 gallons of pure biodiesel (B100) or one biodiesel fuel-use credit for every 2,250 gallons of $20 \%$ biodiesel blends (B20) 5 they purchase for use in MD/ HD vehicles (10 CFR sections 490.701702). In MY 2018, covered fleets reported using just over 7.9 million gallons of B100 in $\mathrm{B} 20$ or higher blends, thus allowing these fleets to earn a total of 1,646 biodiesel fuel use credits.

Some fleets have also begun to use renewable diesel, which is counted as B100. The credits awarded likely do not reflect the total amount of biodiesel purchased because each fleet may apply biodiesel fuel use credits to meet no more than $50 \%$ of its annual $\mathrm{AFV}$ - acquisition requirements. It is likely that some fleets are reporting only the amount of biodiesel that will earn them those credits rather than reporting all of their biodiesel use.

\section{Credit Use and Acquisition}

Covered fleets earn bankable credits by acquiring more AFVs than are required in a given model year. Fleets may then use these credits to address future AFV-acquisition

\section{Alternative Fuel Infrastructure}

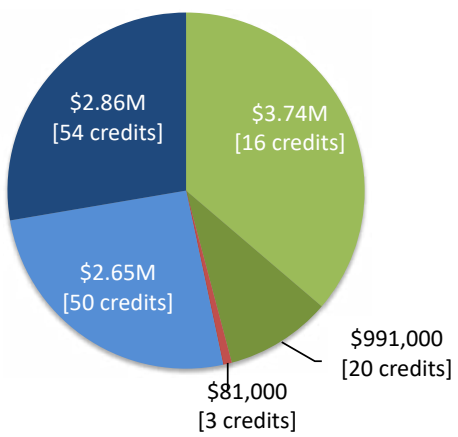

- CNG Not Publicly Available Electricity Not Publicly Available

- CNG Publicly Available

- Electricity Publicly Available

- LPG Not Publicly Available

\section{Non-Road Equipment}

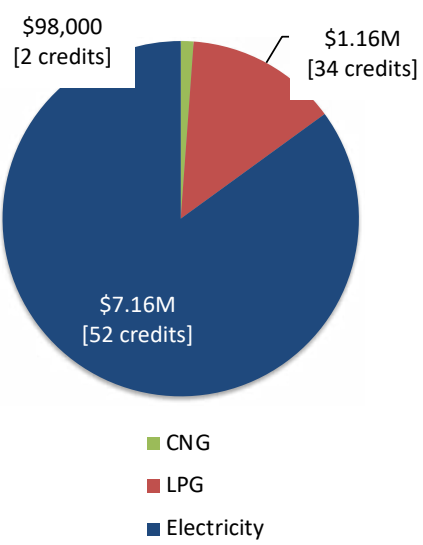

Figure 3. Alternative fuel infrastructure and non-road equipment.

requirements, or they may sell the credits to fleets that have acquired an insufficient number of AFVs in a particular model year. In MY 2018, fleets exceeded their AFV-acquisition requirements and earned 6,948 credits for future use. Fleets also used 2,435 banked credits to comply with EPAct - somewhat less than the number of credits applied in MY 2017, when fleets used 2,656 banked credits. There were 10 transactions between covered fleets involving the transfer of 140 banked credits. The number of credits exchanged in MY 2017 was 188, somewhat more than in MY 2018. However, the number of transactions was the same in MY 2018 and MY 2017 (10).

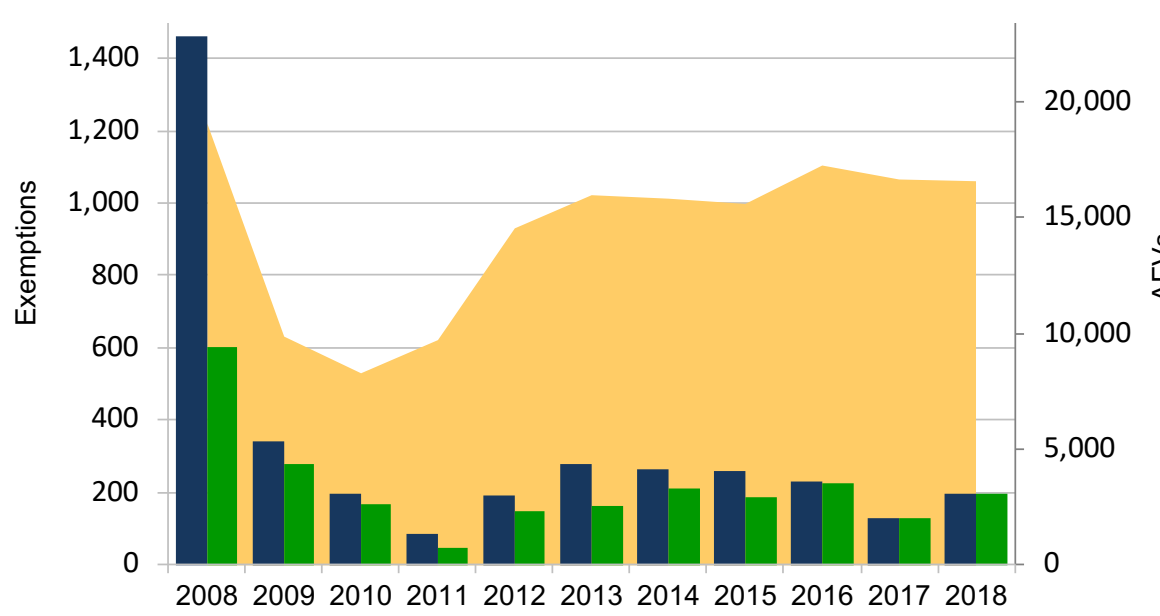

Total Annual AFV-Acquisition Requirement $\quad$ Exemptions Requested $\quad$ Exemptions Granted

Figure 4. Annual exemptions requested and granted compared to total AFV acquisition requirement.

\section{Investments}

Covered fleets may earn credits for investments in non-road equipment, alternative fuel infrastructure, and emerging technologies related to electric drive vehicles. ${ }^{6}$ Generally, fleets will earn one credit for every $\$ 25,000$ invested. For the alternative fuel infrastructure category - that is, investments in MY 2018 for which covered fleets reported amounts and sought creditsfunds were spent for $\mathrm{CNG}$, and electricity infrastructure. The total spent on public and non-public infrastructure totaled more than $\$ 10$ million. Fleets earned $143^{7}$ credits for these investments. In MY 2018, covered fleets earned $88^{7}$ credits for investments in alternative- fueled, non-road equipment.

\section{Exemptions}

Overall, granted exemptions ${ }^{8}$ in MY 2018 represented a little over 1\% (total number of exemptions granted/total AFV-acquisition requirements) of covered fleets' compliance credit activity. In MY 2018, state and

\footnotetext{
${ }^{5}$ Learn more about calculating biodiesel fuel use credits at epact.energy.gov/pdfs/biodiesel_guidance.pdf

${ }^{6}$ Learn more about investments at epact.energy.gov/pdfs/ investments.pdf.

${ }^{7}$ Fleets also earned credits for pooling of infrastructure and non-road equipment investments that were individually less than $\$ 25,000$, but exceeded the threshold when aggregated. These pooled credits are not shown on the figure.

${ }^{8}$ Exemptions are detailed on the EPAct website at epact. energy.gov/exemptions.
} 
alternative fuel provider fleets received a total of 197 vehicle exemptions - more than the 131 exemptions granted in MY 2017.

Only four fleets sought exemptions in MY 2018. MY 2007 was the peak year for fleets seeking exemptions, when 43 fleets filed for exemptions.

In MY 2018, four fleets received 197 vehicle exemptions. Over the period from 2000 to 2008 , the average yearly number of exemptions requested was over 1,400, and the average number granted was over 1,000 . In contrast, the average yearly number of exemptions requested from 2009 to 2018 was about 218 , with an average of 176 granted. With the increased availability of AFV models and opportunities to earn AFV-acquisition credits under the program, and increased availability of alternative fueling infrastructure across the nation, the number of exemption requests and granted requests should continue to remain low.

\section{Alternative Compliance Results}

MY 2018 marked the eleventh year that covered state and alternative fuel provider fleets could choose DOE's Alternative Compliance option in lieu of complying with EPAct via Standard Compliance. EPAct 2005 established Alternative Compliance, and the option was put in place by DOE's final rulemaking in March 2007 for initial application in MY 2008.

Under Alternative Compliance, fleets employ petroleum reduction measures in lieu of acquiring AFVs under Standard Compliance. Examples of these petroleum reduction measures are included in the chart above. Fleets must obtain a waiver from DOE for the upcoming model year. To receive a waiver, fleets first must submit an intent to apply for a waiver to DOE; they then must follow up with that intent by filing a complete waiver application that includes a plan showing how they intend to reduce their fleets' petroleum consumption.

\section{Achievements in MY 2018}

DOE approved waiver applications for eight fleets to participate in Alternative

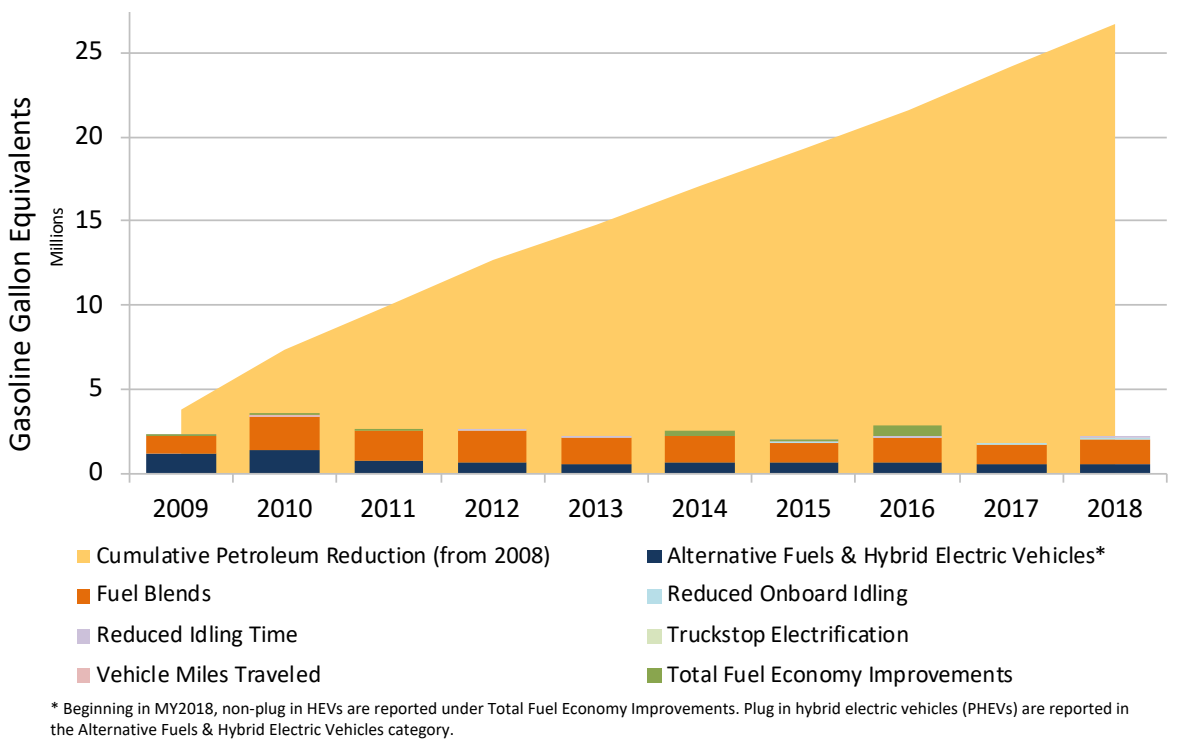

Figure 5. Petroleum reductions achieved by Alternative Compliance fleets.
Compliance for MY 2018. Seven of these fleets were able to meet their required petroleum fuel use reductions for MY 2018. The remaining fleet applied banked gasoline gallon equivalents (GGEs) to meet its requirement.

The eight fleets' total required petroleum use reduction for MY 2018 was 2,049,406 GGEs, and their total actual petroleum consumption reduction was $2,421,914$ GGEs, exceeding the aggregate petroleum reduction requirement as a group by 372,508 GGEs. The fleets met and exceeded their petroleum reduction goals using the following methods (percentages based on the total petroleum reduction reported [amount required plus additional achieved]):

- Using biodiesel blends (62\%)

- Using alternative fuels (21\%)

- Improving fuel economy (14\%)

- Limiting engine idling time (3\%).

The petroleum reduction the eight fleets using Alternative Compliance achieved in MY 2018 was slightly more than the petroleum reduction the eight fleets in the same program achieved in MY 2017.

\section{Notices of Intent}

During MY 2018, DOE received 12 notices of intent to apply for a waiver from Standard Compliance for MY 2019. This is the same number of notices of intent that were received in MY 2017 for MY 2018 compliance.

\section{For More Information}

Learn more about the State and Alternative Fuel Provider Fleet Program and Standard and Alternative Compliance at epact.energy. gov, or contact the Regulatory Information Line at 202-586-9171 or regulatory.info@ nrel.gov.

\section{U.S. DEPARTMENT OF ENIERCY}

Office of

ENERGY EFFICIENCY \& RENEWABLE ENERGY

For more information, visit: epact.energy.gov

DOE/GO 102020-5270 • June 2020 